Article

\title{
Work-Family Arrangement and Conflict: Do Individual Gender Role Attitudes and National Gender Culture Matter?
}

\author{
Christina Bornatici and Marieke Heers * \\ FORS-Swiss Centre of Expertise in the Social Sciences, University of Lausanne, 1015 Lausanne, Switzerland; \\ E-Mails: christina.bornatici@fors.unil.ch (C.B.), marieke.heers@fors.unil.ch (M.H.) \\ * Corresponding author
}

Submitted: 26 February 2020 | Accepted: 29 June 2020 | Published: 9 October 2020

\begin{abstract}
This article examines the relationship between couples' work-family arrangement and individuals' perceived work-family conflict (WFC), considering individuals' attitudes towards gender roles and national gender culture in 37 countries $(N=15,114)$. Previous research has shown that WFC depends on work and family demands and has mostly accounted for absolute time spent in paid and domestic work. We hypothesize that WFC depends on couples' work-family arrangement in terms of time spent in paid, domestic and care work. We further expect that the relationship between couples' work-family arrangement and WFC depends on individuals' gender attitudes and national gender culture. To test these assumptions, we use the ISSP-2012 data and apply multilevel linear regression analyses. The findings indicate that an egalitarian work-family arrangement-that is, sharing paid, domestic and care work equally with one's partner-is associated with lower levels of WFC. Moreover, individuals with egalitarian gender attitudes and an egalitarian work-family arrangement experience less WFC than individuals with inconsistent attitudes and behaviours. Individuals with consistent traditional attitudes and behaviours experience the most conflict. Finally, a more egalitarian gender culture relates to less WFC. Cross-level interactions indicate that the relationship between work-family arrangement and WFC is not mediated by countries' gender culture.
\end{abstract}

\section{Keywords}

care work; couple dynamics; gender culture; gender role; work-family arrangement; work-family conflict

Issue

This article is part of the issue "Division of Labour within Families, Work-Life Conflict and Family Policy" edited by Michael Ochsner (FORS Lausanne, Switzerland), Ivett Szalma (Centre for Social Sciences, Hungarian Academy of Sciences Centre of Excellence, Hungary/Corvinus University of Budapest, Hungary) and Judit Takács (Centre for Social Sciences, Hungarian Academy of Sciences Centre of Excellence, Hungary/KWI Essen, Germany).

(C) 2020 by the authors; licensee Cogitatio (Lisbon, Portugal). This article is licensed under a Creative Commons Attribution 4.0 International License (CC BY).

\section{Introduction}

Women and men are increasingly involved in the paid work and the family domain (i.e., domestic and care work). Reconciling these domains in a way that allows individuals to develop a work-family balance fitting their expectations and needs remains an every-day challenge. When the demands in the work domain interfere with those in the family domain, individuals might experience work-family conflict (WFC). This has become a major policy concern as there is a growing understanding that WFC results into lower satisfaction and productivity at work, lower satisfaction with family life as well as lower well-being and health (Amstad, Meier, Fasel, Elfering, \& Semmer, 2011; Notten, Grunow, \& Verbakel, 2017). A rich array of studies has identified the antecedents and consequences of WFC (e.g., Amstad et al., 2011; Byron, 2005). In this study, we elaborate on how having multiple roles in different life domains (i.e., paid, domestic and care work) relates to WFC. 
First, we investigate the relationship between couples' work-family arrangement (WFA)-each partner's involvement in paid, domestic and care work-and individually perceived WFC. Work-family responsibilities are arranged between partners; this can have the explicit or implicit aim of achieving a low level of WFC for each person. Thus, not only individuals' but also their partners' involvement in paid and unpaid work and the resulting demands matter for WFC.

The literature has shown that having higher work and family workloads results in more WFC. Most studies account for individuals' hours spent in paid and domestic work. Spending longer hours in paid and domestic work are important antecedents of WFC (e.g., Byron, 2005; Ollo-López \& Goñi-Legaz, 2017). However, there is a lack of evidence on the absolute time spent on care (see Nomaguchi, 2011). Care demands are mostly measured in terms of the number and age of the children in the household (e.g., Grönlund \& Öun, 2010; Ruppanner, 2013). Moreover, the literature has mainly focused on partners' involvement in paid work (e.g., Notten et al., 2017; Steiber, 2009), some included partners' involvement in domestic work (Crompton \& Lyonette, 2006; Nordenmark, 2013), but no study has analysed partners' involvement in care work. To complete the picture, Bianchi, Sayer, Milkie, and Robinson (2012) called for analyses of women's and men's allocation of time in the three domains and suggested to pay particular attention to care work, which represents the actual barrier to women's employment.

Second, we investigate to what extent the association between WFA and WFC depends on individuals' attitudes towards gender role equality; that is individuals' level of support for an equal division of paid and unpaid work between women and men. This is important as gender attitudes shape individuals' preferred and actual WFA (Davis \& Greenstein, 2009; Pollmann-Schult, 2016). Prior studies on the association of gender attitudes and WFC provide inconclusive results (Nordenmark, 2013; Ruppanner, 2013; Steiber, 2009); we examine the indirect association between gender attitudes and WFC while considering couples' WFA.

Third, we account for national gender culture, that is the norms and values that shape the "desirable and 'correct' form of gender relations and division of labour between women and men" (Pfau-Effinger, 1998, p. 150). According to Powell, Francesco, and Ling (2009), gender culture is a major factor in the work-family interface. While both national culture and individual gender attitudes influence individuals' opportunities and behaviours (Treas \& Tai, 2016; Uunk, 2015), norms affect couples differently in different countries (Aboim, 2010). Thus, it is particularly relevant to evaluate how different gender cultures-in combination with individual gender attitudes and WFAs - relate to perceived WFC.

Taken together, this study addresses WFC that may arise from couples' WFA, taking into account individuals' attitudes towards gender roles and national gender cul- ture. Our research question is: To what extent is an egalitarian WFA between partners related to WFC, and to what extent is this association affected by egalitarian gender role attitudes and an egalitarian gender culture (EGC)?

Our contribution to the literature on WFC is threefold. First, as advocated by Bianchi et al. (2012), we account for couples' arrangement of paid, domestic and care work. To have a comprehensive understanding of the association between WFA and WFC, we assess couples' general WFA and their arrangement in each domain. Second, we analyse the conditional role of gender attitudes in this relationship, which has only been considered by one study on a limited number of countries (Crompton \& Lyonette, 2006). Third, we acknowledge that individuals' behaviours are shaped by social, cultural and political contexts (Lachance-Grzela \& Bouchard, 2010). While prior research on WFC has mainly focussed on institutionalist explanations and evaluated family policy regimes (e.g., Grönlund \& Öun, 2010; Notten et al., 2017), our focus is on gender culture, which constitutes "an important analytical dimension" for WFC (Hagqvist, Gådin, \& Nordenmark, 2017, p. 794).

\section{Theoretical Framework}

\subsection{Multiple Roles in Work, Family, and WFC}

Having multiple roles is considered to lead to role conflict and WFC, or role expansion and increased fulfilment. While the focus of our study is on role conflict, we also briefly elaborate on role expansion as both are related (Grönlund \& Öun, 2010).

Based on role theory, having to fulfil multiple roles in the work and family domains can lead to excessive and competing demands arising from those roles. As individuals' time and energy are limited (Goode, 1960), meeting all expectations is challenging and compliance with one role can make compliance with the other role(s) difficult or impossible (Kahn, Wolfe, Quinn, Snoek, \& Rosenthal, 1964). In this sense, WFC is defined as "a form of interrole conflict in which the role pressures from the work and family domains are mutually incompatible" (Greenhaus \& Beutell, 1985, p. 77). Therefore, when work demands interfere negatively with the fulfilment of family life and/or family demands interfere negatively with the completion of employment, individuals experience role conflict and, as a consequence, WFC. Past studies found that higher work and family demands relate to higher levels of WFC (e.g., Byron, 2005; Notten et al., 2017; Ruppanner, 2013).

Another stream of studies posits that having multiple roles can produce positive outcomes and spillover as "problems and failures in one sphere can be compensated for by success and satisfaction in the other" (Grönlund \& Öun, 2010, p. 180). According to this perspective-referred to as role expansion, role enrichment or role enhancement-the combination of work and family roles can generate social support, greater sat- 
isfaction with work and family, higher levels of well-being and better health (Barnett \& Hyde, 2001; Greenhaus \& Powell, 2006). Yet, beneficial effects of multiple roles seem to only occur under specific conditions and vanish when the demands of one role are too excessive, or when the perceived role quality is low (Barnett \& Hyde, 2001). The literature on role expansion acknowledges the risk of role conflict and defines work-family balance as the achievement of a high level of role expansion and a minimal level of role conflict (Sirgy \& Lee, 2018).

A meta-analysis suggests that role expansion is negatively related to WFC (Byron, 2005). Grönlund and Öun (2010) do not consider the direct relationship between role expansion and role conflict but are interested in how the same antecedents either result into the one or the other when also accounting for the policy regime. They find that individuals with lower work and family demands are more likely to experience lower role conflict and higher role expansion. However, while individuals having higher demands experience higher role conflict, in dual-earner family policy regimes they also experience higher role expansion. These results suggest that the negative relationship between role expansion and WFC is more likely to occur when demands are low. In addition to the level of demands, other factors, such as individual gender attitudes and the national gender culture, may also imply lower WFC generated by role expansion.

\subsection{Couples' WFA and WFC}

While the literature has shown that WFC depends on individuals' work and family demands, individuals' perceived WFC might also depend on their partners' involvement in paid, domestic and care work. Therefore, the responsibilities and contributions of both partners in a couple must be considered. Past studies mainly focus on partners' involvement in paid work and reveal mixed results on its relationship with individuals' WFC. Notten et al. (2017) found that, for both women and men, having a full-time working partner reduces WFC compared to having a nonworking partner. This corresponds to Steiber's (2009) results showing that women experience more WFC when their partners work shorter hours. Nordenmark (2013), on the other hand, found that men experience more WFC when their partners spend longer hours in paid and domestic work.

Most studies account for the absolute time the partner spends in paid and domestic work. Yet, to understand how partners' demands and their possible support affect perceived WFC, one needs to take into account couples' general WFA, as well as the relative time both partners spend in each domain, including care work. We assume that within couples, work and family responsibilities can be arranged to achieve a lower level of WFC for both partners and to improve their work-family balance. Partners can specialize in paid or unpaid work, or equally share employment, domestic and care work. Sharing roles and responsibilities in the work and fam- ily domains more equally may affect WFC in two opposite ways: as suggested by role theory, having to fulfil multiple roles may create competing demands and, thereby, result in role conflict. On the other hand, if both partners share the workloads more equally, the risk of an overwhelming demand towards one partner is lower, which implies that individuals' report lower levels of WFC (Allen, French, Dumani, \& Shockley, 2015; Ollo-López \& Goñi-Legaz, 2017). To investigate the underlying mechanism, we test the following hypothesis:

Hypothesis 1: Individuals sharing paid, domestic and care work about equally with their partner report less WFC.

The relationship between having to fulfil multiple roles and WFC may differ by gender and it can be assumed that women experience higher levels of WFC (Shockley, Shen, DeNunzio, Arvan, \& Knudsen, 2017). Yet, the literature reveals mixed results. Byron (2005), for example, found no significant relationship between gender and WFC, while others found that women experience more conflict (e.g., Notten et al., 2017; Steiber, 2009).

\subsection{WFA and Conflict: The Role of Gender Attitudes}

Previous research has identified attitudes towards gender roles as an important factor in individuals' preferred and actual WFA (e.g., Davis \& Greenstein, 2009; Pollmann-Schult, 2016). Individuals with more traditional attitudes favour a male breadwinner and female homemaker arrangement, whereas individuals with more egalitarian attitudes prefer an equal share between partners in each domain. Past studies have mainly analysed the direct relationship between gender role attitudes and WFC and found mixed results: Steiber (2009) found that men's egalitarian attitudes are related to more WFC, while Ruppanner (2013) found that egalitarian attitudes are related to less WFC for women and men. Accounting for national gender culture, Nordenmark (2013) found that gender attitudes are not significantly related to WFC. In addition to directly affecting WFC, gender attitudes may affect WFC indirectly.

More egalitarian attitudes relate to women's higher involvement in paid work (Steiber \& Haas, 2009) as well as more equally sharing housework (Aassve, Fuochi, \& Mencarini, 2014) and childcare (Monna \& Gauthier, 2008). However, gender attitudes do not always match couples' WFA: Individuals' actual WFA may deviate from their gender role attitudes due to institutional and normative constraints as well as pragmatic decisions (BühImann, Elcheroth, \& Tettamanti, 2009; Treas \& Tai, 2016). Such inconsistency may lead individuals to experience more WFC, while consistent attitudes and behaviours may rather decrease WFC. Hence, the relationship between couples' WFA and individually perceived WFC might by conditional on individuals' attitudes towards gender roles. 
Individuals with egalitarian attitudes value having dual roles in the work and family domains and, up to a certain level of demands, experience it as role expansion rather than role conflict. Indeed, egalitarians seem to benefit more from having multiple roles than traditionalists (Barnett \& Hyde, 2001). At the same time, individuals with egalitarian attitudes are more likely to experience a specialized WFA as unfair (Greenstein, 1996). Therefore, egalitarian individuals are likely to perceive higher levels of WFC when paid and unpaid work is not shared equally. Conversely, individuals with traditional attitudes consider that men should principally contribute to the family as providers and women as homemakers and caretakers. Hence, traditional individuals would perceive having dual roles as preventing them from fully fulfilling their 'proper' role. Accordingly, individuals with traditional attitudes and an egalitarian division of paid and unpaid work probably experience more role conflict and, consequently, more WFC than traditional individuals with more specialized roles.

The only study that has analysed the relationship between WFA and WFC conditional on gender role attitudes is the one by Crompton and Lyonette (2006). They found that consistent egalitarians (i.e., individuals whose egalitarian gender attitudes are consistent with their egalitarian WFA) have lower levels of WFC than consistent traditionalists. The latter is contrary to our expectation (namely, consistent traditionalists experience less WFC). Yet, their sample included only full-time employees and the consistent and inconsistent groups were defined based on individuals' gender attitudes and the division of domestic work; paid and care work were not considered. Given that all women in the sample were working full-time, it was not possible to capture traditional women's attitude-behaviour consistency in terms of paid and unpaid work. Here, we shed more light on the relationship between attitude-behaviour consistency and WFC by considering paid, domestic and care work. To this end, we test the following hypothesis:

Hypothesis 2: Individuals with consistent gender role attitudes and WFA report lower levels of conflict than individuals with inconsistent attitudes and WFA.

\subsection{National Gender Culture, Couples' WFA, and WFC}

A large body of literature has analysed how gender cultures influence individuals' gender attitudes (e.g., Davis \& Greenstein, 2009) and frame couples' WFA (e.g., Aboim, 2010; Treas \& Tai, 2016; Uunk, 2015). These studies generally show that more gender-egalitarian cultures encourage equality in terms of work and family roles and responsibilities. Indeed, in these contexts, there are higher normative expectations for men to contribute equally to unpaid work (Ollo-López \& Goñi-Legaz, 2017). Furthermore, women, and particularly mothers, are strongly involved in the labour market as EGCs and policies encourage it (Bühlmann et al., 2009; Uunk,
2015). On the other hand, in countries with more traditional gender cultures, institutions are relatively unsupportive of egalitarian WFAs and there are stronger social pressures to act in line with the predominant gender culture (Aboim, 2010).

While multiple studies have assessed the relationship between gender culture and couples' division of paid and unpaid work, and despite an acknowledgement that gender culture is an important factor in the work-family interface (Powell et al., 2009), few studies have explicitly measured gender culture and evaluated its relationship with WFC. Hagqvist et al. (2017) found that in countries with more gender-egalitarian norms towards women's employment, individuals report lower levels of WFC. On the contrary, Nordenmark (2013) found that more EGCs relate to higher WFC. Other studies do not find a significant relationship between gender culture and WFC (Allen et al., 2015; Ollo-López \& Goñi-Legaz, 2017).

Again, Crompton and Lyonette's (2006) study provides valuable insights. The authors analysed the interconnectedness between individuals' gender attitudes, couples' division of domestic labour and WFC in five European countries. They tested neither gender culture nor policy regimes directly but assessed the effect of living in five countries. Their results indicate that individuals in Finland and Norway experience less WFC than those in France while all three countries have developed family policies encouraging dual-earner family models. The authors attribute this difference to varying societally embedded and gendered norms about couples' division of labour, with an inconsistency in France between gender culture and behaviours. France has an EGC and a traditional division of domestic work prevails; the EGC in the Nordic countries, on the other hand, is consistent with a more egalitarian division of domestic work. Moreover, Crompton and Lyonette find that in Portugal, where gender culture and behaviours are more traditional, the traditional division of domestic work did not relate to WFC. This suggests that the relationship between WFC and behaviour differs according to countries' gender culture. In this study, we disentangle how couples' WFA is related to WFC when gender culture-across a large set of European and non-European countries-is taken into account. Moreover, we test whether the relationship between attitude-behaviour (in)consistency and WFC depends on gender culture. In the empirical section that follows below, we test the following hypotheses:

Hypothesis 3: When couples' WFA is consistent with the prevailing gender culture, individuals experience less WFC. On the contrary, when the arrangement is inconsistent with the gender culture, individuals experience more conflict.

Hypothesis 4: When attitudes and WFA are consistent with the prevailing gender culture, individuals experience less WFC. On the contrary, when attitudes and 
arrangement are inconsistent with the gender culture, individuals experience more conflict.

\section{Methodology}

\subsection{Data}

We use the 2012 International Social Survey Programme data (ISSP Research Group, 2016). These data fit well with our research question as they include a validated measure on perceived WFC (Breyer \& Bluemke, 2016), information on attitudes towards gender roles and on both partners' time allocation in paid, domestic and care work. Our sample consists of working respondents aged 18 to 64 who cohabit with their partner. Information on partners is obtained from the respondents. We include individuals with and without children; individuals without childcare responsibilities also experience WFC (Grant-Vallone \& Donaldson, 2001). In total, 41 countries participated in the ISSP-2012. Four countries with missing information on respondents' cohabitation status or the number of children were removed. We dropped individuals with missing information on any of the variables included in the analyses. The analysis sample consists of 15,114 respondents in 37 countries.

\subsection{Measures}

The dependent variable, WFC, is measured with four items: (1) I have come home from work too tired to do chores which need to be done; (2) It has been difficult for me to fulfil my family responsibilities because of the amount of time I have spent on my job; (3) I have arrived at work too tired to function well because of household work I had done; (4) I have found it difficult to concentrate at work because of my family responsibilities.

The original four-point scale ranges from 'several times per week' to 'never.' We inverted the scale and summed the items into an index ranging from 0 (no conflict) to 1 (high level of conflict; Cronbach's $\alpha=0.76$ ).

To analyse WFAs, we have constructed three groups of variables. First, we account for the absolute time respondents spend on paid, domestic and care work (weekly hours). Care includes childcare and care of other family members. Values higher than 70 hours were recoded to 70 hours (corresponding to Fuwa \& Cohen, 2007). These variables are used as control variables. Based on these absolute time indicators, three dichotomous variables indicate whether both partners spend an approximately equal amount of time on paid, domestic and care work. Namely, based on respondents' and partners' weekly hours spent on each domain, we first calculated the respective ratios. Positive values indicate that the woman spends more time on that respective domain and negative values indicate that the man spends more time on that domain. Second, couples with a repartition of around 0 (from -0.2 to 0.2 ) were categorized as spending an approximately equal amount of time on each domain $(=1$; in all other cases $=0$ ). Respondents reporting that their partners and themselves spent no hours on either domestic or care work were categorized as sharing equally (coded 1). As having no care obligations (i.e., spending 0 hours per week) is different from equally sharing care work, we run robustness analyses that only include couples with care obligations $(n=12,258)$. The variables take into account the relative time both partners spend on each domain and account for the specific arrangement in each domain separately. Finally, a categorical variable accounts for couples' general WFA (taking into account the division of paid and unpaid work) and indicates if the general arrangement is traditional (the man is more involved in paid work and the woman in unpaid work), modern traditional (equal involvement in paid work, but the woman does more unpaid work), egalitarian (equal involvement in paid and unpaid work) or if the couple has a different arrangement (e.g., the woman is more involved in paid work and/or the man in unpaid work).

To measure gender role attitudes, we have combined eight items assessing respondents' attitudes towards gender roles. Respondents had to indicate if they agree or disagree (on a five-point scale) with the following statements: (1) A working mother can establish just as warm and secure a relationship with her children as a mother who does not work; (2) a pre-school child is likely to suffer if his or her mother works; (3) all in all, family life suffers when the woman has a fulltime job; (4) a job is all right, but what most women really want is a home and children; (5) both the man and woman should contribute to the household income; (6) a man's job is to earn money and a woman's job is to look after the home and family. The respondents were also asked whether women should work part-time, fulltime or not at all, both (7) when there is a child under school age and (8) after the youngest child starts school. These items have been previously used to measure gender role attitudes (e.g., Fuwa \& Cohen, 2007). We first compute a gender role attitudes scale ranging from 1 (traditional-not at all in favour of gender role equality) to 5 (egalitarian-totally in favour of gender role equality; Cronbach's $\alpha=0.77$ ). Based on this scale, we have created a three-category measure distinguishing individuals with traditional ( 1 to 2.5 ), neutral ( 2.5 to 3.5 ) and egalitarian (3.5 to 5 ) gender attitudes.

We created two types of attitude-behaviour consistency measures. The first measure captures the consistency between individual gender attitudes and couples' general WFA to create four groups of individuals: the consistent egalitarians (individuals with egalitarian WFA and attitudes), the consistent traditionalists (traditional arrangement and attitudes), the consistent modern traditionalists (modern traditional arrangement and traditional attitudes) and individuals with inconsistent WFA and attitudes. For individuals with traditional attitudes, we differentiate traditional and modern traditional arrangements to capture the difference between women who are involved in paid work as much as their partner 
and those being less involved. Second, we create measures for each specific arrangement in paid, domestic and care work and distinguish individuals with consistent egalitarian, consistent traditional and inconsistent attitude-behaviour.

To measure national gender culture, we have constructed an indicator corresponding to the proportion of respondents with egalitarian attitudes towards gender roles in each country. This aggregated country-level measure of individual-level gender role attitudes is based on all respondents in the analysed countries ( $n=55,709$ ), i.e., it also includes individuals who are excluded from our analysis sample. Hence, it represents each country's level of support for gender egalitarianism.

Finally, the literature suggests that higher demands in work and family, as well as being younger or more educated, predicts higher levels of WFC (e.g., Ruppanner, 2013; Steiber, 2009). Thus, we include the following control variables: respondents' age, educational level, work status and the presence and age of the youngest child in the household. We also control for respondents' sex.

\subsection{Analytic Strategy}

Much of the cross-national research on WFC has grouped countries into family policy regimes to compare national contexts (e.g., Grönlund \& Öun, 2010), but it has been argued that a more nuanced perspective must be taken (Hagqvist et al., 2017). Hence, we examine the relationship between couples' WFA, individual gender attitudes, national gender culture and WFC without clustering countries into policy groups.

Given that individuals (Level 1 ) are nested in countries (Level 2), we apply multilevel linear regression analysis (MLA). MLA allows to account for the nonindependence of individuals and to simultaneously examine micro-and macro-level factors (Snijders \& Bosker, 2012). We have specified several random intercept models adding the variables step-by-step and verified if the model fit improves. While we comment on most models, due to limitations of space, we only display the most important ones. We present the intraclass correlation coefficient (ICC) and the deviance (in terms of log likelihood [-2 LL] values). We cannot make causal statements but reveal associations.

\section{Results}

\subsection{Descriptive Statistics}

Table 1 displays the descriptive statistics. The sample includes slightly more men than women. Most respondents have a traditional or modern traditional WFA. Around half report that they and their partners spend an equal amount of time on paid and care work, but only around a quarter spend an equal amount of time on domestic work. Considering gender attitudes, 37\% are in favour of egalitarian gender roles and $15 \%$ have tradi- tional attitudes. Most respondents have inconsistent attitudes and behaviours, both when accounting for the general or domain-specific arrangement. There are more consistent egalitarians in paid and care work than in domestic work.

There is considerable variation across countries' gender culture (Figure 1). Nordic countries have the most egalitarian culture, led by Sweden, where $62 \%$ of the population favours gender equality. India has the least EGC with only $3 \%$ of the population having egalitarian attitudes towards gender roles. We also observe considerable differences in terms of perceived levels of WFC across countries. Venezuelans experience by far the highest level of conflict (0.67), followed by Bulgarians (0.46) and Indians (0.44). Individuals in Switzerland (0.20) and the Netherlands (0.21) report the lowest levels of WFC. Both countries are characterised by a high share of parttime female employment (OECD, 2018). Overall, a less EGC relates to higher levels of WFC. Lower levels of support for gender egalitarianism correlate with lower proportions of individuals with an egalitarian WFA.

\subsection{The Relationship between WFA and WFC}

The results of the MLAs are presented in Tables 2 and 3. The 'empty model' indicates that an average person experiences 0.32 WFC on a scale ranging from 0 to 1 . The ICC reveals that 12.4 percent of the individual variation in WFC is explained by living in different countries (Model 1.1, Table 2).

To test whether sharing the workload equally relates to reduced WFC (Hypothesis 1) we first assess couples' general WFA (egalitarian, modern traditional, traditional, and other). Compared to individuals in couples with an egalitarian arrangement, those in any of the other three arrangements perceive more WFC (Model 1.2). This supports Hypothesis 1.

To have a more comprehensive understanding of how the specific domains affect WFC, we test a set of models with dichotomous variables indicating if both partners spend an approximately equal amount of time in paid, domestic and care work. First, we include each indicator in separate regressions and find that sharing paid work and care work equally is related to less WFC, while sharing domestic work equally is not significantly related to WFC (not shown). When we consider paid and domestic work in the same regression (not shown)-the domains that have been mostly considered by previous studies (Nordenmark, 2013; Notten et al., 2017; Steiber \& Haas, 2009) - we find that equally sharing paid work relates to less conflict. However, this ignores the challenges that couples face regarding care work. Once we include all three domains in the same regression, only an egalitarian sharing of care work is related to less perceived WFC, while equally sharing paid and domestic work is not significantly related to WFC (Model 1.3). To conclude, it is mainly equally sharing care work with the partner that is related to lower WFC, while equally sharing paid and 
Table 1. Descriptive statistics for the analysis sample.

\begin{tabular}{|c|c|c|}
\hline & Mean or \% & SD \\
\hline \multicolumn{3}{|l|}{ Individual-level variables } \\
\hline WFC & 0.30 & 0.24 \\
\hline \multicolumn{3}{|l|}{ General WFA } \\
\hline Traditional & $27 \%$ & \\
\hline Modern traditional & $31 \%$ & \\
\hline Egalitarian & $20 \%$ & \\
\hline Other & $22 \%$ & \\
\hline Equally sharing paid work & $55 \%$ & \\
\hline Equally sharing domestic work & $26 \%$ & \\
\hline Equally sharing care work & $47 \%$ & \\
\hline \multicolumn{3}{|l|}{ Gender role attitudes } \\
\hline Traditional & $15 \%$ & \\
\hline Neutral & $48 \%$ & \\
\hline Egalitarian & $37 \%$ & \\
\hline \multicolumn{3}{|c|}{ Attitudes-behaviour consistency in general WFA } \\
\hline Inconsistent & $80 \%$ & \\
\hline Consistent egalitarian & $11 \%$ & \\
\hline Consistent modern traditional & $4 \%$ & \\
\hline Consistent traditional & $6 \%$ & \\
\hline \multicolumn{3}{|c|}{ Attitudes-behaviour consistency in paid work } \\
\hline Inconsistent & $68 \%$ & \\
\hline Consistent egalitarian & $24 \%$ & \\
\hline Consistent traditional & $8 \%$ & \\
\hline \multicolumn{3}{|c|}{ Attitudes-behaviour consistency in domestic work } \\
\hline Inconsistent & $77 \%$ & \\
\hline Consistent egalitarian & $12 \%$ & \\
\hline Consistent traditional & $11 \%$ & \\
\hline \multicolumn{3}{|c|}{ Attitudes-behaviour consistency in care work } \\
\hline Inconsistent & $70 \%$ & \\
\hline Consistent egalitarian & $20 \%$ & \\
\hline Consistent traditional & $10 \%$ & \\
\hline \multicolumn{3}{|l|}{ Control variables } \\
\hline Woman & $46 \%$ & \\
\hline Age & 43.41 & 10.40 \\
\hline \multicolumn{3}{|l|}{ Educational level } \\
\hline Lower & $26 \%$ & \\
\hline Upper secondary & $39 \%$ & \\
\hline Tertiary & $35 \%$ & \\
\hline Hours in paid work & 42.01 & 12.94 \\
\hline Hours in domestic work & 12.45 & 10.88 \\
\hline Hours in care work & 13.80 & 16.93 \\
\hline \multicolumn{3}{|l|}{ Work status } \\
\hline Employee & $60 \%$ & \\
\hline Employee with supervision task & $23 \%$ & \\
\hline Self-employed & $17 \%$ & \\
\hline \multicolumn{3}{|l|}{ Children at home } \\
\hline None & $43 \%$ & \\
\hline Child 0-below school age & $27 \%$ & \\
\hline Child school age-17 & $30 \%$ & \\
\hline \multicolumn{3}{|l|}{ Country-level variable } \\
\hline$E G C$ & 0.31 & 0.17 \\
\hline $\mathrm{N}$ individuals / countries & & \\
\hline
\end{tabular}

Source: ISSP Research Group (2016). 


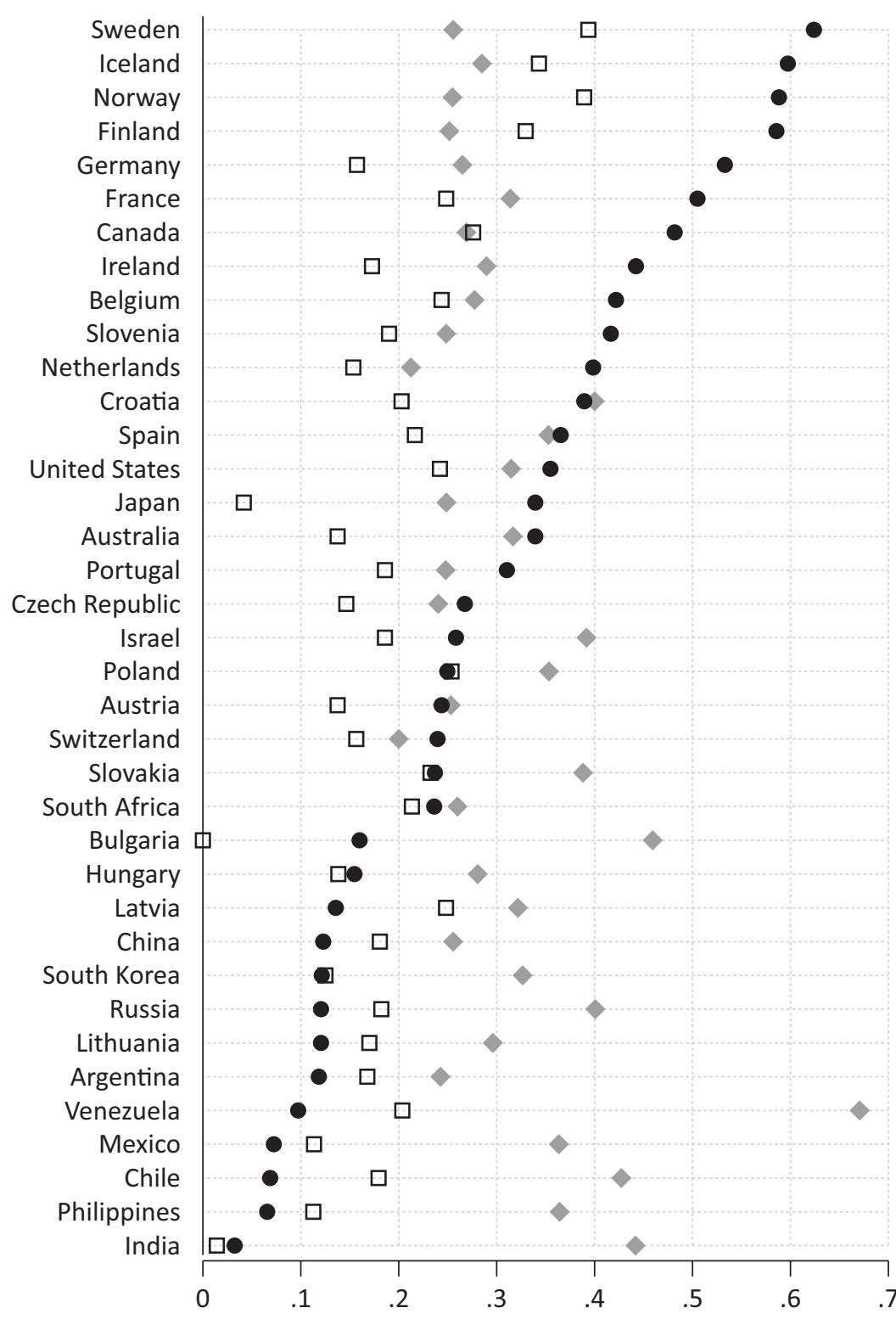

- Egalitarian gender culture

$\square$ Egalitarian work-family arrangement

Work-family conflict

Figure 1. Mean EGC, egalitarian WFA and WFC, by country.

domestic work is not related to WFC. This completes the results for the models with the categorical WFA indicator and further supports Hypothesis 1.

\subsection{Individuals' Attitude-Behaviour Consistency and WFC}

Next, we are interested in how couples' WFA relates to perceived WFC when accounting for individual gender attitudes. Compared to individuals with egalitarian attitudes, individuals holding traditional or neutral attitudes experience more WFC (Model 2.1, Table 3), and those holding neutral attitudes report less WFC than those with traditional attitudes (not shown).

After having established that gender attitudes are related to WFC, we turn to Hypothesis 2 stipulating that individuals whose WFA matches their gender attitudes perceive less WFC than individuals with inconsistent attitudes and WFAs. We consider two measures for attitude-behaviour consistency. First, for couples' general arrangement we find that compared to individuals with inconsistent attitudes and arrangements (the largest group), consistent egalitarian individuals report less WFC, while those with a consistent modern traditional or a consistent traditional arrangement report more conflict (Model 2.2).

Second, we examine consistency in each domain. We estimate models assessing attitude-behaviour consistency in paid, domestic and care work in separate regressions (not shown); then, we account for paid and domestic work jointly (not shown) and finally for all three domains in the same regression (Model 2.3). Overall, compared to individuals with inconsistent attitudes and behaviours, individuals with egalitarian attitudes and behaviours in either paid, domestic or care work experience less conflict. However, egalitarian consistency in domestic work is only significant when it is assessed separately. Individuals with traditional attitudes and sharing paid 
Table 2. MLAs predicting WFC from couples' WFA and gender culture.

\begin{tabular}{|c|c|c|c|c|c|c|c|c|c|c|c|c|c|c|}
\hline & \multicolumn{2}{|c|}{ Model 1.1} & \multicolumn{2}{|c|}{ Model 1.2} & \multicolumn{2}{|c|}{ Model 1.3} & \multicolumn{2}{|c|}{ Model 1.4} & \multicolumn{2}{|c|}{ Model 1.5} & \multicolumn{2}{|c|}{ Model 1.6} & \multicolumn{2}{|c|}{ Model 1.7} \\
\hline & Coef. & S.E. & Coef. & S.E. & Coef. & S.E. & Coef. & S.E. & Coef. & S.E. & Coef. & S.E. & Coef. & S.E. \\
\hline Constant & 0.317 & $(0.014)^{* * *}$ & 0.217 & $(0.019)^{* * *}$ & 0.247 & $(0.019)^{* * *}$ & 0.385 & $(0.025)^{* * *}$ & 0.276 & $(0.028)^{* * *}$ & 0.306 & $(0.028)^{* * *}$ & 0.213 & $(0.018)^{* * *}$ \\
\hline \multicolumn{15}{|l|}{ Individual level variables } \\
\hline \multicolumn{15}{|l|}{ General WFA } \\
\hline Traditional & & & 0.014 & $(0.006)^{*}$ & & & & & 0.013 & $(0.006)^{*}$ & & & 0.013 & $(0.006)$ \\
\hline Modern traditional & & & 0.013 & $(0.005)^{*}$ & & & & & 0.013 & $(0.005)^{*}$ & & & 0.012 & $(0.005)$ \\
\hline Egalitarian & & & ref. & & & & & & ref. & & & & ref. & \\
\hline Other & & & 0.019 & $(0.006)^{* *}$ & & & & & 0.019 & $(0.006)^{* *}$ & & & 0.019 & $(0.006)^{* * *}$ \\
\hline Equally sharing paid work & & & & & -0.006 & $(0.004)$ & & & & & -0.005 & $(0.004)$ & & \\
\hline Equally sharing domestic w & ork & & & & -0.002 & $(0.004)$ & & & & & -0.002 & $(0.004)$ & & \\
\hline Equally sharing care work & & & & & -0.023 & $(0.004)^{* * *}$ & & & & & -0.022 & $(0.004)^{* * *}$ & & \\
\hline \multicolumn{15}{|l|}{ Country level variable } \\
\hline$E G C$ & & & & & & & -0.234 & $(0.074)^{* *}$ & -0.203 & $(0.074)^{* *}$ & -0.201 & $(0.074)^{* *}$ & -0.201 & $(0.076)^{* *}$ \\
\hline \multicolumn{15}{|l|}{ Cross-level interactions } \\
\hline Traditional WFA x EGC & & & & & & & & & & & & & -0.022 & $(0.033)$ \\
\hline Modern traditional WFA & $x$ EGC & & & & & & & & & & & & 0.031 & $(0.030)$ \\
\hline Egalitarian WFA x EGC & & & & & & & & & & & & & ref. & \\
\hline Other WFA x EGC & & & & & & & & & & & & & -0.018 & $(0.033)$ \\
\hline \multicolumn{15}{|l|}{ Variance components } \\
\hline Country variance & 0.007 & $(0.002)^{* * *}$ & 0.007 & $(0.002)^{* * *}$ & 0.007 & $(0.002)^{* * *}$ & 0.006 & $(0.001)^{* * *}$ & 0.006 & $(0.001)^{* * *}$ & 0.006 & $(0.001)^{* * *}$ & 0.006 & $(0.001)^{* * *}$ \\
\hline Residual & 0.052 & $(0.001)^{* * *}$ & 0.051 & $(0.001)^{* * *}$ & 0.051 & $(0.001)^{* * *}$ & 0.052 & $(0.001)^{* * *}$ & 0.051 & $(0.001)^{* * *}$ & 0.051 & $(0.001)^{* * *}$ & 0.051 & $(0.001)^{* * *}$ \\
\hline ICC & \multicolumn{2}{|c|}{0.124} & \multicolumn{2}{|c|}{0.119} & \multicolumn{2}{|c|}{0.119} & \multicolumn{2}{|c|}{0.100} & \multicolumn{2}{|c|}{0.101} & \multicolumn{2}{|c|}{0.101} & \multicolumn{2}{|c|}{0.100} \\
\hline Deviance & \multicolumn{2}{|c|}{-1516.305} & \multicolumn{2}{|c|}{-2005.824} & \multicolumn{2}{|c|}{-2034.705} & \multicolumn{2}{|c|}{-1525.132} & \multicolumn{2}{|c|}{-2012.756} & \multicolumn{2}{|c|}{-2041.526} & \multicolumn{2}{|c|}{-2016.609} \\
\hline
\end{tabular}

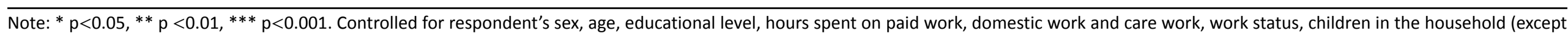
Model 1.1). Source: ISSP Research Group (2016). 
Table 3. MLAs predicting WFC from attitude-behaviour consistency and gender culture.

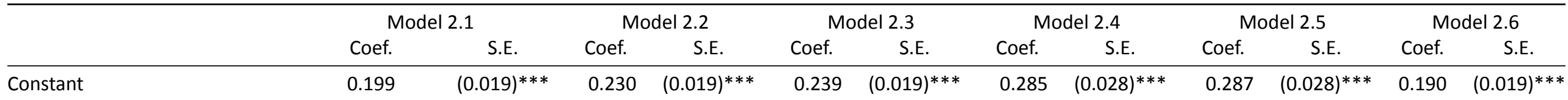

Individual level variables

Gender role attitudes

$\begin{array}{lcc}\text { Traditional } & 0.063 & (0.006)^{* * *} \\ \text { Neutral } & 0.039 & (0.004)^{* * *} \\ \text { Egalitarian } & \text { ref. } & \end{array}$

Egalitarian

ref.

Attitudes-behaviour consistency in general WFA

Inconsistent

Consistent egalitarian

Consistent modern traditional

Consistent traditional

Attitudes-behaviour consistency in paid work

Inconsistent

Consistent egalitarian

Consistent traditional

Attitudes-behaviour consistency in domestic work

Inconsistent

Consistent egalitarian

Consistent traditional

Attitudes-behaviour consistency in care work

Inconsistent

Consistent egalitarian

Consistent traditional

\begin{aligned} \multicolumn{1}{r}{ ref. } & \\ -0.033 & $(0.006)^{* * *} \\ 0.060 & (0.010)^{* * *} \\ 0.016 & (0.008)^{*}\end{aligned}$

ref.

$\begin{aligned}-0.033 & (0.006)^{* * *} \\ 0.060 & (0.010)^{* * *} \\ 0.016 & (0.008)^{*}\end{aligned}$

0.036

ref.

$0.120 \quad(0.016)^{* * *}$

$0.049(0.011)^{* * *}$

$\begin{array}{cl}\text { ref. } & \\ -0.023 & (0.006)^{* * *} \\ -0.024 & (0.009)^{* *} \\ & \\ \text { ref. } & \\ -0.004 & (0.007) \\ 0.030 & (0.010)^{* *} \\ & \\ \text { ref. } & \\ -0.025 & (0.006)^{* * *} \\ 0.021 & (0.010)^{*}\end{array}$

ref.

$-0.023(0.006)^{* * *}$

$-0.024(0.009)^{* *}$

ref.

$-0.004 \quad(0.007)$

$0.030(0.010)^{* *}$

ref.

$-0.025(0.006)^{* * *}$

$0.021(0.010)^{*}$ 
Table 3. (Cont.) MLAs predicting WFC from attitude-behaviour consistency and gender culture.

\begin{tabular}{|c|c|c|c|c|c|c|c|c|c|c|c|c|}
\hline & \multicolumn{2}{|c|}{ Model 2.1} & \multicolumn{2}{|c|}{ Model 2.2} & \multicolumn{2}{|c|}{ Model 2.3} & \multicolumn{2}{|c|}{ Model 2.4} & \multicolumn{2}{|c|}{ Model 2.5} & \multicolumn{2}{|c|}{ Model 2.6} \\
\hline & Coef. & S.E. & Coef. & S.E. & Coef. & S.E. & Coef. & S.E. & Coef. & S.E. & Coef. & S.E. \\
\hline \multicolumn{13}{|l|}{ Country level variable } \\
\hline EGC & & & & & & & -0.187 & $(0.074)^{*}$ & -0.164 & $(0.074)^{*}$ & -0.160 & $(0.082)$ \\
\hline \multicolumn{13}{|c|}{ Cross-level interactions } \\
\hline Inconsistent att.-behav. in general WFA & $A \times E G C$ & & & & & & & & & & -0.037 & $(0.039)$ \\
\hline Consistent egalitarian $\times$ EGC & & & & & & & & & & & ref. & \\
\hline Consistent modern traditional x EGC & & & & & & & & & & & 0.242 & $(0.080)^{* *}$ \\
\hline Consistent traditional x EGC & & & & & & & & & & & -0.063 & $(0.066)$ \\
\hline \multicolumn{13}{|l|}{ Variance components } \\
\hline Country variance & 0.006 & $(0.002)^{* * *}$ & 0.007 & $(0.002)^{* * *}$ & 0.007 & $(0.002)^{* * *}$ & 0.006 & $(0.001)^{* * *}$ & 0.006 & $(0.001)^{* * *}$ & 0.006 & $(0.001)^{* * *}$ \\
\hline Residual & 0.050 & $(0.001)^{* * *}$ & 0.051 & $(0.001)^{* * *}$ & 0.050 & $(0.001)^{* * *}$ & 0.051 & $(0.001)^{* * *}$ & 0.050 & $(0.001)^{* * *}$ & 0.051 & $(0.001)^{* * *}$ \\
\hline ICC & \multicolumn{2}{|c|}{0.113} & \multicolumn{2}{|c|}{0.119} & \multicolumn{2}{|c|}{0.116} & \multicolumn{2}{|c|}{0.103} & \multicolumn{2}{|c|}{0.103} & \multicolumn{2}{|c|}{0.103} \\
\hline Deviance & \multicolumn{2}{|c|}{-2115.648} & \multicolumn{2}{|c|}{-2066.854} & \multicolumn{2}{|c|}{-2130.508} & \multicolumn{2}{|c|}{-2072.739} & \multicolumn{2}{|c|}{-2135.109} & \multicolumn{2}{|c|}{-2088.982} \\
\hline
\end{tabular}

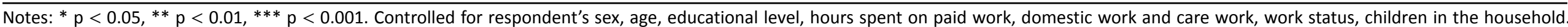
Source: ISSP Research Group (2016). 
work traditionally also experience less conflict, whereas traditional consistency in domestic and care work is related to more conflict. Taken together, we find mixed support for Hypothesis 2: While consistent egalitarians experience the least conflict, consistent traditionalists experience the most WFC.

\subsection{Gender Culture, WFA, and WFC}

The theoretical and empirical literature suggests that national gender culture contributes to shaping how couples share different types of workloads. Therefore, we now assess the extent to which gender culture plays a role in the above-observed relationship between WFA, gender attitudes (as well as consistency thereof) and WFC. Again, we build the model step-by-step following the same procedure as in sections 4.2 and 4.3. We start with a model that only accounts for gender culture (ICC $=10 \%)$. On average, WFC is lower in countries with more EGCs (Model 1.4). This is confirmed when the control variables are added and when assessing couples' general WFA (Model 1.5) or the domain-specific arrangement (Model 1.6). When we assess overall (Model 2.4) and domain-specific consistency (Model 2.5), a more EGC is still associated with reduced levels of WFC. The results presented in sections 4.2 and 4.3 are confirmed when accounting for gender culture.

Hypothesis 3 posits that the relationship between WFC and WFA differs according to gender culture. To test this, we include cross-level interactions between gender culture and general (Model 1.7, which, like Model 2.6, included a mean centred variable for national gender culture) and domain-specific arrangement (not shown). The interactions are not significant (revealed by Wald-tests). Hence, the relationship between WFA and WFC does not differ according to gender culture and Hypothesis 3 is rejected.

To understand if the relationship between attitudebehaviour consistency and WFC depends on the intensity of countries' gender egalitarianism (Hypothesis 4) we test interactions between gender culture and attitudebehaviour consistency (Model 2.6). The interaction is significant (Wald test: $\chi_{3}^{2}=16.25, p<0.01$ ). Compared to consistent egalitarians, consistent modern traditional individuals experience more conflict in countries with more EGCs (which has been verified graphically but it is not shown here). We have also tested interactions between gender culture and consistency in each domain (not shown)-they are insignificant (again indicated by Wald-tests). Hence, Hypothesis 4 is confirmed for the general arrangement and concerning egalitarian and modern traditional consistency.

\subsection{Observations on Control Variables and Robustness Analyses}

Across models, spending more hours in paid and care work as well as having children in the household relates to higher levels of WFC. Spending more time on domestic work is not significant. This confirms earlier studies (e.g., Notten et al., 2017; Ruppanner, 2013). In all models, women experience significantly more WFC than men.

To keep couples without children in the sample, in the main analyses, individuals without care obligations were classified as 'sharing care work equally,' while we controlled for the presence of children. To assess the robustness of those findings, we test the models including the variables 'sharing care work equally' and 'attitudebehaviour consistency in care work' with a restricted sample considering only individuals with care obligations ( $n=12,258)$. The above findings are confirmed.

\section{Discussion and Conclusion}

This study has analysed how variations in couples' WFA are associated with individually perceived WFC, and what role individuals' gender attitudes and national gender culture play in this relationship. It set out with the assumption that WFC is not only directly affected by individuals' workloads related to the paid, domestic and care domains, but that it also depends on couples' WFA. Moreover, we expected the relationship between couples' WFA and WFC to depend on individuals' gender role attitudes and national gender culture.

First, we investigated the relationship between couples' WFA and individuals' perceived WFC. Previous research has shown that individually perceived WFC depends on individuals' work and family demands (e.g., Byron, 2005; Notten et al., 2017; Ruppanner, 2013), while partners' demands and their possible support were not systematically taken into account. We posit that considering couples' WFA provides a more comprehensive understanding of the relationship between individuals' work and family demands and WFC. The results regarding couples' general division of paid and unpaid work show that individuals having an egalitarian WFA experience lower levels of WFC, confirming Hypothesis 1 . As it is likely that sharing paid work equally affects WFC differently from sharing domestic or care work equally, we have also accounted for couples' domain-specific arrangements. Indeed, sharing care work equally is related to lower WFC, while sharing paid and domestic work equally does not predict perceived WFC. A potential explanation is that care work is perceived as more rewarding than routine domestic tasks (Bianchi et al., 2012). This suggests that sharing care work plays an important role in generating role expansion: Compared to the traditional repartition of activities, men are more involved in care work and share this responsibility with women. Consequently, women can be more involved in paid work or other activities. Future research should investigate if the relationship between care and WFC differs according to the specific care task (e.g., providing personal care vs. more enjoyable activities) and to whom care is provided (Byron, 2005). Corroborating Bianchi et al.'s (2012) suggestion, our findings show that analyses should ac- 
count for both partners' time spent in paid, domestic and care work.

Second, we analysed how couples' WFA relates to perceived WFC when accounting for individual gender attitudes and attitude-behaviour consistency. We hypothesised that individuals experience less WFC when attitudes are consistent with their arrangement. Yet, this assumption does not hold under all conditions: Attitudebehaviour consistency is only related to less WFC when attitudes and arrangements (both general and domainspecific) are egalitarian (i.e., consistent egalitarians). On the contrary, individuals having traditional attitudes and arrangements (i.e., consistent traditionalists) experience more WFC than individuals having inconsistent attitudes and arrangements. Hypothesis 2 is partly supported. An attitude-behaviour fit seems to benefit consistent egalitarians, while it is rather detrimental for consistent traditionalists. The concept of role expansion is useful to explain this difference: consistent egalitarians experience higher role expansion when having multiple roles (Barnett \& Hyde, 2001). Furthermore, they receive greater support from their partner in unpaid work, which may lead to lower WFC (Allen et al., 2015; Ollo-López \& Goñi-Legaz, 2017). Consistent traditionalists, on the other hand, are less likely to experience positive spillover since they are mainly involved in one domain. Also, the pressure to completely fulfil a role might be higher when one partner is mainly (or exclusively) responsible for a specific role. Our results lend further support to those of Crompton and Lyonette (2006). We extend their findings as we have assessed consistency in terms of paid, domestic and care work, while they have focused on the domestic domain. Overall, gender attitudes play an important role in WFC. They are directly related to WFC: individuals with more egalitarian attitudes experience the lowest level of WFC. Additionally, they affect WFC in their interplay with couples' practices. Our results are robust in showing that egalitarians experience the lowest level of conflict, this holds in terms of attitudes and behaviours and their consistency.

Third, this article has shed light on how the relationship between WFC and WFA varies along countries' gender culture. The results are robust to adding gender culture to the analyses and reveal that individuals living in more egalitarian countries tend to experience lower levels of conflict. The finding that individuals in countries with a more EGC perceive lower levels of WFC reinforces previous research (Hagqvist et al., 2017). An important contribution was to assess if gender culture mediates the relationship between couples' WFA (general and domain-specific) and WFC. Gender culture does not mediate those relationships when we only consider arrangements (rejecting Hypothesis 3). Once gender attitudes are accounted for, the picture changes. Cross-level interactions between attitude-behaviour consistency and gender culture suggest that compared to consistent egalitarians, consistent modern traditional individuals experience more conflict when support for gender egal- itarianism is stronger (partly confirming Hypothesis 4). Thus, consistent egalitarians living in more EGCs experience the least conflict. This lends support to the suggestion that egalitarian attitudes and arrangements can be most efficiently implemented in contexts that support it (Steiber \& Haas, 2009).

The present study has some limitations. The sample consists of respondents who are in paid work. This implies that populations that are particularly at risk of experiencing WFC, that is, those who do not work to avoid conflict, are excluded. ISSP-2012 did not ask if the reason for not working is a strategy to avoid WFC. We suggest collecting this information in future surveys. Moreover, the measures for gender role attitudes focus on women's roles, leaving men's roles and other aspects of gender equality out of the picture. Future research should provide a finer assessment of gender attitudes: a differentiation of attitudes towards sharing paid work (e.g., women's and mothers' role in employment, men working part-time) equally and attitudes towards sharing domestic and care work (e.g., women's and mothers' role as housewife and carer and men's role in unpaid work) would be valuable to analyse individuals' attitudebehaviour consistency. Additionally, the current study has focused on WFC; to better disentangle the mechanisms, future research should analyse how the above findings differ for work-to-family and family-to-work interference. Finally, besides gender culture, other macrolevel factors (e.g., family policy measures, proportion of mothers in employment) should be included to assess the role of contexts more comprehensively.

To conclude, our results suggest that for individually experienced WFC, not only individuals' workloads and couples' WFA but also individual gender role attitudes and national gender culture matter. Our results indicate that egalitarian individuals, both in terms of attitudes and arrangements as well as consistency thereof tend to experience lower levels of WFC. Moreover, individuals tend to experience less WFC in countries with stronger support for gender egalitarianism.

Given that the antecedents of role conflict arise from multiple levels, initiatives and efforts to reduce WFC have to be implemented at the individual, couple and national policy level. Policies aimed at decreasing WFC and its negative societal consequences should take individual attitudes into account; it is important to note that policies may also affect norms concerning gender roles and attitudes (Brighouse \& Olin Wright, 2008; Stickney \& Konrad, 2012). Particular attention should be paid to how policies encourage partners to share care tasks more equally. To reduce WFC, policymakers should strengthen policies that favour the involvement of both partners in (child)care. Overall, men and particularly fathers should be more extensively considered by family policies. Finally, employers also have an important role to play in supporting fathers to be more involved in the family domain. 


\section{Acknowledgments}

The authors have contributed equally to the article and their names are listed alphabetically. The authors thank the editors and the anonymous reviewers for their helpful comments.

\section{Conflict of Interests}

The authors declare no conflict of interests.

\section{References}

Aassve, A., Fuochi, G., \& Mencarini, L. (2014). Desperate housework: Relative resources, time availability, economic dependency, and gender ideology across Europe. Journal of Family Issues, 35(8), 1000-1022. https://doi.org/10.1177\%2F0192513X14522248

Aboim, S. (2010). Gender cultures and the division of labour in contemporary Europe: A cross-national perspective. The Sociological Review, 58(2), 171-196. https://doi.org/10.1111/j.1467-954X.2010.01899.x

Allen, T. D., French, K. A., Dumani, S., \& Shockley, K. M. (2015). Meta-analysis of work-family conflict mean differences: Does national context matter? Journal of Vocational Behavior, 90, 90-100. https://doi.org/ 10.1016/j.jvb.2015.07.006

Amstad, F. T., Meier, L. L., Fasel, U., Elfering, A., \& Semmer, N. K. (2011). A meta-analysis of work-family conflict and various outcomes with a special emphasis on cross-domain versus matching-domain relations. Journal of Occupational Health Psychology, 16(2), 151-169. https://doi.org/10.1037/a0022170

Barnett, R. C., \& Hyde, J. S. (2001). Women, men, work, and family: An expansionist theory. American Psychologist, 56(10), 781-796. https://doi.org/10.1037/ 0003-066X.56.10.781

Bianchi, S. M., Sayer, L. C., Milkie, M. A., \& Robinson, J. P. (2012). Housework: Who did, does or will do it, and how much does it matter? Social Forces, 91(1), 55-63. https://doi.org/10.1093/sf/sos120

Breyer, B., \& Bluemke, M. (2016). Work-family conflict scale (ISSP). Zusammenstellung sozialwissenschaftlicher Items und Skalen. https://doi.org/ $10.6102 /$ zis243

Brighouse, H., \& Olin Wright, E. (2008). Strong gender egalitarianism. Politics \& Society, 36(3), 360-372. https://doi.org/10.1177/0032329208320566

Bühlmann, F., Elcheroth, G., \& Tettamanti, M. (2009). The division of labour among European couples: The effects of life course and welfare policy on value-practice configurations. European Sociological Review, 26(1), 49-66. https://doi.org/10.1093/esr/ jcp004

Byron, K. (2005). A meta-analytic review of work-family conflict and its antecedents. Journal of Vocational Behavior, 67(2), 169-198. https://doi.org/10.1016/ j.jvb.2004.08.009
Crompton, R., \& Lyonette, C. (2006). Work-life 'balance' in Europe. Acta Sociologica, 49(4), 379-393. https:// doi.org/10.1177/0001699306071680

Davis, S. N., \& Greenstein, T. N. (2009). Gender ideology: Components, predictors, and consequences. Annual Review of Sociology, 35(1), 87-105. https://doi.org/ 10.1146/annurev-soc-070308-115920

Fuwa, M., \& Cohen, P. N. (2007). Housework and social policy. Social Science Research, 36(2), 512-530. https://doi.org/10.1016/j.ssresearch.2006.04.005

Goode, W. J. (1960). A theory of role strain. American Sociological Review, 25(4), 483-496. https://doi.org/ 10.2307/2092933

Grant-Vallone, E. J., \& Donaldson, S. I. (2001). Consequences of work-family conflict on employee wellbeing over time. Work \& Stress, 15(3), 214-226. https://doi.org/10.1080/02678370110066544

Greenhaus, J. H., \& Beutell, N. J. (1985). Sources of conflict between work and family roles. The Academy of Management Review, 10(1), 76-88. https://doi.org/ 10.2307/258214

Greenhaus, J. H., \& Powell, G. N. (2006). When work and family are allies: A theory of work-family enrichment. The Academy of Management Review, 31(1), 72-92. https://doi.org/10.2307/20159186

Greenstein, T. N. (1996). Gender ideology and perceptions of the fairness of the division of household labor: Effects on marital quality. Social Forces, 74(3), 1029-1042. https://doi.org/10.2307/2580391

Grönlund, A., \& Öun, I. (2010). Rethinking work-family conflict: Dual-earner policies, role conflict and role expansion in Western Europe. Journal of European Social Policy, 20(3), 179-195. https://doi.org/ 10.1177/0958928710364431

Hagqvist, E., Gådin, K. G., \& Nordenmark, M. (2017). Work-family conflict and well-being across Europe: The role of gender context. Social Indicators Research, 132(2), 785-797. https://doi.org/10.1007/ s11205-016-1301-x

ISSP Research Group. (2016). International social survey programme: Family and changing gender roles IV-ISSP 2012 [Data set]. https://doi.org/10.4232/ 1.12661

Kahn, R. L., Wolfe, D. M., Quinn, P. R., Snoek, J. D., \& Rosenthal, R. A. (1964). Organizational stress: Studies in role conflict and ambiguity. New York, NY: Wiley.

Lachance-Grzela, M., \& Bouchard, G. (2010). Why do women do the lion's share of housework? A decade of research. Sex Roles, 63(11), 767-780. https://doi. org/10.1007/s11199-010-9797-z

Monna, B., \& Gauthier, A. H. (2008). A review of the literature on the social and economic determinants of parental time. Journal of Family and Economic Issues, 29(4), 634-653. https://doi.org/10.1007/ s10834-008-9121-z

Nomaguchi, K. M. (2011). Marital status, gender, and home-to-job conflict among employed parents. Jour- 
nal of Family Issues, 33(3), 271-294. https://doi.org/ 10.1177/0192513X11415613

Nordenmark, M. (2013). Disagreement about division of household labour and experiences of work-family conflict in different gender regimes. Multidisciplinary Journal of Gender Studies, 2(3), 205-232.

Notten, N., Grunow, D., \& Verbakel, E. (2017). Social policies and families in stress: Gender and educational differences in work-family conflict from a European perspective. Social Indicators Research, 132(3), 1281-1305. https://doi.org/10.1007/ s11205-016-1344-z

OECD. (2018). Part-time employment rate. OECD Data. Retrieved from https://data.oecd.org/emp/parttime-employment-rate.htm

Ollo-López, A., \& Goñi-Legaz, S. (2017). Differences in work-family conflict: Which individual and national factors explain them? The International Journal of Human Resource Management, 28(3), 499-525. https://doi.org/10.1080/09585192.2015.1118141

Pfau-Effinger, B. (1998). Gender cultures and the gender arrangement: A theoretical framework for cross-national gender research. Innovation: The European Journal of Social Science Research, 11(2), 147-166. https://doi.org/10.1080/13511610.1998. 9968559

Pollmann-Schult, M. (2016). What mothers want: The impact of structural and cultural factors on mothers' preferred working hours in Western Europe. Advances in Life Course Research, 29, 16-25. https:// doi.org/10.1016/j.alcr.2015.11.002

Powell, G. N., Francesco, A. M., \& Ling, Y. (2009). Toward culture-sensitive theories of the work-family interface. Journal of Organizational Behavior, 30(5), 597-616. https://doi.org/10.1002/job.568

Ruppanner, L. (2013). Conflict between work and family:
An investigation of four policy measures. Social Indicators Research, 110(1), 327-347. https://doi.org/ 10.1007/s11205-011-9933-3

Shockley, K. M., Shen, W., DeNunzio, M. M., Arvan, M. L., \& Knudsen, E. A. (2017). Disentangling the relationship between gender and work-family conflict: An integration of theoretical perspectives using meta-analytic methods. Journal of Applied Psychology, 102(12), 1601-1635. https://doi.org/10.1037/ apl0000246

Sirgy, M. J., \& Lee, D.-J. (2018). Work-life balance: An integrative review. Applied Research in Quality of Life, 13(1), 229-254. https://doi.org/10.1007/ s11482-017-9509-8

Snijders, T., \& Bosker, R. (2012). Multilevel models. Thousand Oaks, CA: Sage.

Steiber, N. (2009). Reported levels of time-based and strain-based conflict between work and family roles in Europe: A multilevel approach. Social Indicators Research, 93(3), 469-488.

Steiber, N., \& Haas, B. (2009). Ideals or compromises? The attitude-behaviour relationship in mothers' employment. Socio-Economic Review, 7(4), 639-668. https://doi.org/10.1093/ser/mwp015

Stickney, L. T., \& Konrad, A. M. (2012). Societal institutions and work and family gender-role attitudes. Organization Management Journal, 9(4), 236-246. https://doi.org/10.1080/15416518.2012.738528

Treas, J., \& Tai, T. (2016). Gender inequality in housework across 20 European nations: Lessons from gender stratification theories. Sex Roles, 74(11), 495-511. https://doi.org/10.1007/s11199-015-0575-9

Uunk, W. (2015). Does the cultural context matter? The effect of a country's gender-role attitudes on female labor supply. European Societies, 17(2), 176-198. https://doi.org/10.1080/14616696.2014.995772

\section{About the Authors}

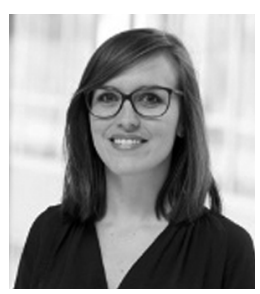

Christina Bornatici is a PhD Candidate at the Faculty of Social and Political Sciences, University of Lausanne. She is also a researcher at FORS-Swiss Centre of Expertise in the Social Sciences. Her research interests lie in the field of gender equality, where she focussed on attitudes towards gender equality and couples' work-family arrangement, which she explores from a gender and a life course perspective.

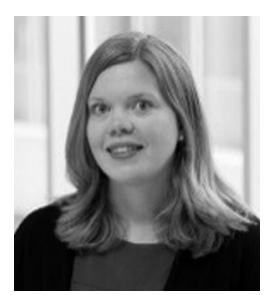

Marieke Heers is a Senior Researcher at FORS-Swiss Centre of Expertise in the Social Sciences, Lausanne. She has obtained a PhD from Maastricht University and worked as a Postdoctoral Fellow at the French Institute for Demographic Research (INED, Paris). Her multidisciplinary research focuses on family contexts and dynamics as well as on social inequalities related to education and migration. 